\title{
Monitoring the effects of doxorubicin on 3D-spheroid tumor cells in real-time
}

This article was published in the following Dove Press journal:

OncoTargets and Therapy

22 November 2016

Number of times this article has been viewed

\author{
NamHuk Baek ${ }^{1, *}$ \\ Ok Won Seo',* \\ MinSung Kim' \\ John Hulme ${ }^{2}$ \\ Seong Soo A An ${ }^{2}$ \\ 'Department of R \& D, NanoEntek \\ Inc., Seoul, Republic of Korea; \\ ${ }^{2}$ Department of BioNano Technology \\ Gachon University, Gyeonggi-do, \\ Republic of Korea \\ *These authors contributed equally \\ to this work
}

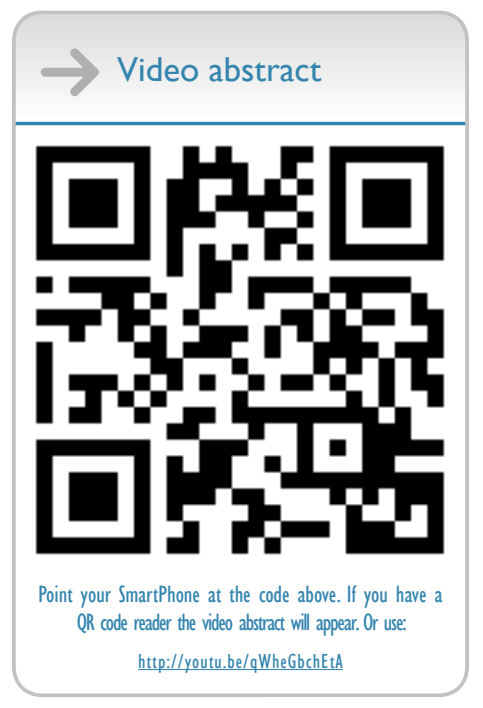

Correspondence: John Hulme; Seong Soo A An

Department of BioNano Technology,

Gachon Medical Research Institute,

Gachon University, (46I-70I)

I342 Sungnam Daero, Sungnamsi,

Republic of Korea

$\mathrm{Tel}+82317508550$

Fax +82317508755

Email flp15@gachon.ac.kr;

seongaan@gachon.ac.kr
Abstract: Recently, increasing numbers of cell culture experiments with 3D spheroids presented better correlating results in vivo than traditional 2D cell culture systems. 3D spheroids could offer a simple and highly reproducible model that would exhibit many characteristics of natural tissue, such as the production of extracellular matrix. In this paper numerous cell lines were screened and selected depending on their ability to form and maintain a spherical shape. The effects of increasing concentrations of doxorubicin (DXR) on the integrity and viability of the selected spheroids were then measured at regular intervals and in real-time. In total 12 cell lines, adenocarcinomic alveolar basal epithelial (A549), muscle (C2C12), prostate (DU145), testis (F9), pituitary epithelial-like (GH3), cervical cancer (HeLa), HeLa contaminant (HEp2), embryo (NIH3T3), embryo (PA317), neuroblastoma (SH-SY5Y), osteosarcoma U2OS, and embryonic kidney cells (293T), were screened. Out of the 12, 8 cell lines, NIH3T3, C2C12, 293T, SH-SY5Y, A549, HeLa, PA317, and U2OS formed regular spheroids and the effects of DXR on these structures were measured at regular intervals. Finally, 5 cell lines, A549, HeLa, SH-SY5Y, U2OS, and 293T, were selected for real-time monitoring and the effects of DXR treatment on their behavior were continuously recorded for 5 days. A potential correlation regarding the effects of DXR on spheroid viability and ATP production was measured on days 1, 3, and 5. Cytotoxicity of DXR seemed to occur after endocytosis, since the cellular activities and ATP productions were still viable after 1 day of the treatment in all spheroids, except SHSY5Y. Both cellular activity and ATP production were halted 3 and 5 days from the start of the treatment in all spheroids. All cell lines maintained their spheroid shape, except SHSY-5, which behaved in an unpredictable manner when exposed to toxic concentrations of DXR. Cytotoxic effects of DXR towards SH-SY5Y seemed to cause degradation of the extracellular matrix, since all cells were dismantled from the spheroid upon cell death. On the other hand, 293 T spheroids revealed retarded cellular activity and ATP productions upon DXR treatment throughout the experiment. Since $293 \mathrm{~T}$ was the embryonic kidney cells, the fast clearance or neutralizations could have made them resistant towards DXR. In conclusion, the same degree of sensitivity from the $2 \mathrm{D}$ system did not translate to a $3 \mathrm{D}$ culture system, resulting in higher IC50 values than the $2 \mathrm{D}$ system. The varying sensitivities and tolerances to drugs could be better understood with a 3D cell culture system.

Keywords: doxorubicin, 3D spheroid, cytotoxicity

\section{Introduction}

Traditionally, monolayer cell cultures were used to monitor behavior and identify effective anti-tumor activities. ${ }^{1}$ Initial work using extracted nerve cells from the notochord of frogs highlighted the challenges of growing 3D cellular structures in vivo. ${ }^{2,3}$ In 1951, the HeLa cell line was established by Master and Lucey et al, which jump-started the full-scale research with animal cells. ${ }^{4,5}$ Since then, various 
types of cell lines were established with detailed understanding of the intracellular mechanisms in 2D cell culture systems. However, limitations of 2D models such as reduced cell-cell or cell-extracellular matrix interactions, absence of blood vessel networks, nerves, and lymph nodes meant significant findings from a monolayer or 2D model did not often translate to results from in vivo models. Overcoming these limitations would bridge the gaps between the conventional 2D cell experiments and animal studies. ${ }^{6,7}$ Fortunately, cells in multicellular spheroids often behave in a similar manner to those found in vivo. It was observed that spheroids $(>200 \mu \mathrm{M})$ could be made, composed of a necrotic core, quiescent intermediate and proliferating periphery regions. Hence, $3 \mathrm{D}$ spheroids could offer a simple and highly reproducible model that would exhibit many characteristics of natural tissues, such as the production of extracellular matrix (ECM) and cell-cell interactions. ${ }^{8}$ Recently, research from Goodman et al demonstrated that the incorporation of ECM modulating collagenase hindered the penetration of polystyrene nano-beads $(20-200 \mathrm{~nm})$ significantly. ${ }^{9}$

To date, the suitability of more than 380 cell lines has been investigated. ${ }^{1}$ Of particular note is the recent work by Vinci et al, in which the spheroids from 40 tumor cell lines were classified in accordance with their compactness, regularity, and presence of friable aggregates. ${ }^{10}$ Ideal spheroids (tight, spherical, and regular) were generated with SF188 glioblastoma tumor cell lines. In another study, A2780, CaOV3, HCT-116, MCF-7, MDA-MB-231, OV2008, SF268, SH-SY5Y, SKOV3, U2OS, along with 70 other cell lines were tested, and a dozen cell lines were confirmed to form 3D spheroids. ${ }^{11-13}$ Several methods are currently used to generate tumor spheroids, such as spinner flasks, ${ }^{14}$ rotary cell culture ${ }^{15}$ and hanging drop, ${ }^{16}$ gel matrix culture, ${ }^{17}$ polymer micro-patterned and polymeric scaffolds. ${ }^{18}$ The technique that most accurately mimics the in vivo cell growth environment was often chosen. The advantage of the $3 \mathrm{D}$ culture is that it permits investigators to accurately model the effects of anti-tumor agents at low cost compared to an in vivo situation. In addition, Fitzgerald et al and Mikhail et al revealed that a 3D culture system was useful in replacing animal models for probing drug resistances. ${ }^{19,20}$

Doxorubicin (DXR) is a widely used anti-tumor agent, which belongs to a class of compounds with similar structures namely, anthracyclines. DXR was shown to have great efficacy in the killing of cancer cells in both liquid and solid tumors. However, the emergence of drug resistance and serious side effects, such as heart damage, has limited its use. The mechanisms by which DXR caused cell death remained unclear. A number of models have been proposed, including ceramide overproduction, DNA adduct formation, oxidative stress and topoisomerase II (TOP II) poisoning. Many examples were also reported in which DXR mediated cell death did not involve Top (II). For example, DXR was shown to evict histones independent of TOP (II) leading to cell death. ${ }^{21}$ Thus, it was highly likely that DXR could kill cancer cells through a variety of mechanisms by inhibiting the synthesis of DNA and RNA, and eventually inhibiting cell divisions, as anti-cancer effects, especially in lung and ovarian cancers. ${ }^{22-28}$

For DXR, cardiomyopathy is the biggest side effect, causing damage to non-dividing cells, where TOP II $\beta$ is the major form. It has been shown that depletion of this subtype protects mice from DXR induced heart failure. ${ }^{29,30}$ Hence, cellular sensitivity would be important in chemotherapy and responsible for all drug administration programs in treating millions of people worldwide. The key problem is that cells at any time within a tumor are in different phases of the cell cycle, yet the majority of drugs are only effective towards tumor cells in the exponential phase. The advantage of DXR is that it induces arrest at all stages of the cell cycle. Recent studies suggested that the reduced form of DXR could induce fragmentations and DNA damage by releasing reactive free radicals, hydroxyl radicals and superoxides. ${ }^{31,32}$ DXR could also induce $\mathrm{H}_{2} \mathrm{O}_{2}$ formation by an iron-mediated reaction, catalyzed by ferredoxin reductase. ${ }^{33}$ A report from Zhang et al showed that the penetration depth of DXR in vivo and in vitro was dependent on the composition and function of the ECM within a given tumor or spheroid. ${ }^{34}$ Understanding these properties would be essential in the development of efficient non-toxic anti-cancer vehicles.

In addition, recent studies ${ }^{35-37}$ using cancer cell lines, Hep3B, HepJ5, ES-2, SKOV-3, OVCAR-3, MCF-7, revealed significant decreases in cell viability after DXR exposure. On the other hand, the same degree of sensitivity from the 2D system did not translate to a $3 \mathrm{D}$ culture system, resulting in higher IC50 values than the 2D system..$^{38}$ Greatly reduced cell viabilities from DXR treatments were observed from uterus/ endometrium cancer (KLE) and colon carcinoma (HCT116), osteogenic sarcoma (Saos-2), and bone osteosarcoma (HOS), which were cultured in 3D system. ${ }^{33-35,39}$ In addition, a significant effect of DXR towards 3D-spheroid forms of Ishikawa human endometrial cancer cells (RL95-2) was revealed by 
measuring cell viability. ${ }^{40}$ Therefore, the varying sensitivities and tolerances to drugs could be better understood with a $3 \mathrm{D}$ cell culture system.

The goal of this study was to monitor and measure the effects of DXR on the growth, shape, movement, energetics, and behavior of tumor 3D-spheroids in real-time over a 5 day period.

\section{Materials and methods Materials}

Cell lines from the American Type Culture Collection, Manassas, VA, USA in the current study were osteosarcoma (U2OS), cervical cancer (HeLa), HeLa contaminant (HEp2), neuroblastoma (SH-SY5Y), muscle (C2C12), pituitary epithelial-like (GH3), embryo (NIH3T3), prostate (DU145), testis (F9), adenocarcinomic alveolar basal epithelial (A549), embryonic kidney (293T), and embryo (PA317) cells. For cell culture, Dulbecco’s Modified Eagle's Medium (DMEM) and Roswell Park Memorial Institute (RPMI) medias, Dulbecco's phosphate-buffered saline (DPBS), fetal bovine serum (FBS), trypsin $(0.05 \%)$-ethylenediaminetetraacetic acid (EDTA) $(0.002 \%)$, and penicillin-streptomycin were from WELGENE, Inc. (Seoul, Republic of Korea). Spheroid microplates (96 well, C. 4520) in 3D-spheroid formation assay was purchased from Corning Inc. (Corning, NY, USA). Dimethyl sulfoxide (DMSO) and DXR for the $3 \mathrm{D}$ cancer spheroid screening and cell anti-proliferation assay were obtained from Sigma-Aldrich Co. (St Louis, MO, USA) and LC Laboratories (Woburn, MA, USA), respectively. CellTiter-Glo ${ }^{\circledR}$ reagent for measuring 3D ATP level in the $3 \mathrm{D}$ cell viability assay was purchased from Promega Corporation (Fitchburg, WI, USA). Automated Fluorescence Cell Counter Arthur (NanoEnTek, Seoul, Korea) was used to count the cells. 3D-spheroid cell cultures were monitored and confirmed by JuLI Stage: Real-Time Cell History Recorder (NanoEnTek). 3D cell viabilities were measured by Infinite Elisa Reader (Tecan, Männedorf, Switzerland).

\section{Cell culture}

A549, C2C12, DU145, F9, GH3, HeLa, HEp2, NIH3T3, PA317, SH-SY5Y, and 293T cells were cultured with DMEM, 10\% FBS and penicillin-streptomycin (1\% 100 units $/ \mathrm{mL})$. RPMI medium with 10\% FBS and penicillin-streptomycin ( $1 \% 100$ units $/ \mathrm{mL}$ ) was used to grow U2OS cells. Media were monitored daily and replaced with fresh media two to three times per week. After washing cells in the flask with DPBS $(\mathrm{pH} 7.0)$, cells were harvested with trypsin $(0.05 \%)$-EDTA
$(0.002 \%)$, and cells were then separated by centrifugation for subsequent cultures with terms of 2 4 days in $75 \mathrm{~mL}$ flasks with 14 20 mL.

\section{Spheroid formation assay}

The following cells, A549, C2C12, DU145, F9, GH3, HeLa, HEp2, NIH3T3, U2OS, PA317, SH-SY5Y, and 293T, were plated with $200 \mu \mathrm{L}$ of $5 \times 10^{3} \sim 3 \times 10^{4}$ cells per well onto Corning ${ }^{\circledR} 96$ Well Spheroid Microplates. After centrifuging the plate at 1000 revolutions per minute (RPM) for 5 minutes, the plate was incubated at $37^{\circ} \mathrm{C}$ for $72 \mathrm{hrs}$ in a $\mathrm{CO}_{2}$ incubator. Formation of spheroid was confirmed by observing under JuLI Stage. ${ }^{30}$

\section{D-spheroid cell anti-proliferation screening}

Eight cell lines were plated and monitored for potential spheroids in the microplates by transferring $100 \mu \mathrm{L}$ of A549 $\left(2 \times 10^{3}\right), \mathrm{C} 2 \mathrm{C} 12\left(1.5 \times 10^{4}\right), \mathrm{HeLa}\left(2 \times 10^{3}\right), \mathrm{NIH} 3 \mathrm{~T} 3\left(1.5 \times 10^{4}\right)$, PA317 $\left(5 \times 10^{3}\right)$, SH-SY5Y $\left(2 \times 10^{3}\right)$, U2OS $\left(2 \times 10^{4}\right)$, and $293 \mathrm{~T}$ $\left(2 \times 10^{3}\right)$ cells onto Corning ${ }^{\circledR} 96$ Well Spheroid Microplates. After centrifuging the plates at 1000 RPM for 5 minutes, cells were incubated for $72 \mathrm{hrs}$ in a $\mathrm{CO}_{2}$ incubator at $37^{\circ} \mathrm{C}$. Subsequently, $100 \mu \mathrm{L}$ of DXR (10 mM in DMSO and media) was added for the final concentrations, 10, 20, 40, 80 and $320 \mu \mathrm{M}$. DMSO in media $(100 \mu \mathrm{L})$ was also added as a control. Next, after centrifuging plates at 1000 RPM for 5 minutes at $37^{\circ} \mathrm{C}$, they were transferred to JuLI Stage in $\mathrm{CO}_{2}$ incubator at $37^{\circ} \mathrm{C}$ for the anti-proliferation screening assay. The photos of the cells and their viabilities were taken and measured with 30 minute intervals for 5 days..$^{31,32}$

\section{D-spheroid cell anti-proliferation assay} U2OS $\left(1 \times 10^{4}\right)$, HeLa $\left(2 \times 10^{3}\right)$, SH-SY5Y $\left(2 \times 10^{3}\right)$, A549 $\left(2 \times 10^{3}\right), 293 \mathrm{~T}\left(2 \times 10^{3}\right)$ cells were plated $(100 \mu \mathrm{L}$ per well $)$ onto Corning ${ }^{\circledR} 96$ Well Spheroid Microplates. The plates were centrifuged at 1000 RPM for 5 minutes and then incubated for $72 \mathrm{hrs}$ in a $\mathrm{CO}_{2}$ incubator at $37^{\circ} \mathrm{C}$. Afterwards, $100 \mu \mathrm{L}$ of DXR (10 mM in DMSO and media) was added to each of the wells for the final concentrations between $20 \sim 100 \mu \mathrm{M}$ for U2OS, HeLa, SH-SY5Y, A549 cells and 10 50 $\mu \mathrm{M}$ for SH-SY5Y and 293T cells. DMSO in media $(100 \mu \mathrm{L})$ was also added as a control. Next, plates were centrifuged at 1000 RPM for 5 minutes at $37^{\circ} \mathrm{C}$, and transferred to JuLI Stage in a $\mathrm{CO}_{2}$ incubator at $37^{\circ} \mathrm{C}$ for the anti-proliferation assay. Cell viabilities and their photos during 5 days of the anti-proliferation assay were measured and taken with 30 minute intervals. 


\section{D cell viability assay}

The 3D cell viability assay was conducted in parallel with the 3D-spheroid cell anti-proliferation assay. In addition to measuring and filming cell viabilities, the effect of DXR treatment on spheroid ATP levels was also measured on days 1,3 and 5 . For the viability assay U2OS $\left(1 \times 10^{4}\right)$, HeLa $\left(2 \times 10^{3}\right)$, SH-SY5Y $\left(2 \times 10^{3}\right)$, A549 $\left(2 \times 10^{3}\right), 293 \mathrm{~T}$ $\left(2 \times 10^{3}\right)$ cells were plated $\left(100 \mu \mathrm{L}\right.$ per well) onto Corning ${ }^{\circledR}$ 96 Well Spheroid Microplates. The plates were centrifuged at 1,000 RPM for 5 minutes and then incubated for $72 \mathrm{hrs}$ in a $\mathrm{CO}_{2}$ incubator at $37^{\circ} \mathrm{C}$. Afterwards, $100 \mu \mathrm{L}$ of DXR (10 mM in DMSO and media) was added to each of the wells for the final concentrations between $20 \sim 100 \mu \mathrm{M}$ for U2OS, HeLa, SH-SY5Y, A549 cells and 293T cells. DMSO in media $(100 \mu \mathrm{L})$ was also added as a control. Next, plates were centrifuged at $1000 \mathrm{RPM}$ for 5 minutes at $37^{\circ} \mathrm{C}$, and transferred to JuLI Stage in a $\mathrm{CO}_{2}$ incubator at $37^{\circ} \mathrm{C}$ for cell viability assay. Media were removed from each well after 1,3 , and 5 days, and luminescence reagent $(100 \mu \mathrm{L}$, 3D CellTiter-Glo ${ }^{\circledR}$ ) was added to each well by following the suggested protocol according to the manufacturer's instructions. After the 30 minutes incubation at room temperature, the luminescence values were measured using an Infinite Elisa Reader (Tecan).

\section{Results and discussion Spheroid formation assay}

As previously mentioned, 12 cell lines were screened and based on their ability to maintain a regular spheroid shape, selected for further investigation. After growing the selected lines for 1 day, the cells were centrifuged and transferred onto the spheroid plate to observe spheroid formation. Eight cell lines, A549, C2C12, HeLa, NIH3T3, U2OS, PA317, SH-SY5Y, and 293T, were chosen. GH3, DU145, F9, and HEp2 did not maintain their spheroid form due to a rapid doubling time and surface interferences. DU145 and F9 cell lines revealed irregular 3D-spheroid shape, see Figure 1. HEp2 behaved similar to the HeLa cell line and was not selected.

\section{D-spheroid cell anti-proliferation screening with DXR}

The selected 8 cell lines for 3D-spheroid cell anti-proliferation assay with DXR were A549, C2C12, HeLa, NIH3T3, PA317, SH-SY5Y, U2OS and 293T. Figure 2 shows the compiled still photos of 8 cell lines 5 days after treatment with various concentrations of DXR, 10, 20, 40, 80 and $320 \mu \mathrm{M}$, and the other compiled shots at 1 and 3 days were included in Figures S1 and S2. The real-time recording of entire experiments will be presented in the Supplementary Video 1.

The size of the A549, HeLa, U2OS and 293T spheroids became slightly larger with increasing concentrations of DXR and the spheroid was maintained with irregular edges. SH-SY5Y spheroid revealed the most dramatic changes in shape and size. The growth and ability to maintain the spheroid shape would be governed by the cell-cell interactions by surface proteins, receptors and ligands through ECM. Even after the composition of spheroids by centrifugation, the cell-cell interactions will create new biochemical compositions with different porosity of ECM, which would affect

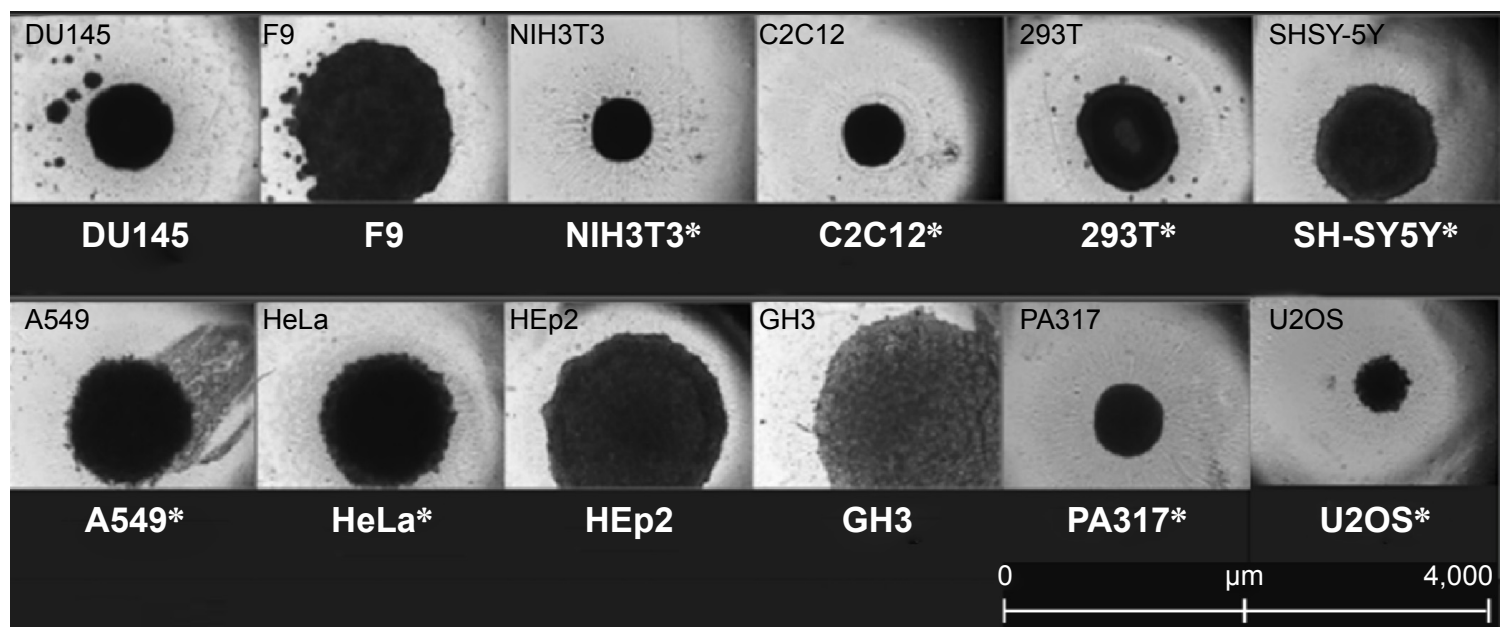

Figure I Formation of 3D-spheroids after 3 days of culturing 12 cell lines: prostate (DUI45), testis (F9), embryo (NIH3T3), muscle (C2CI2), embryonic kidney (293T), neuroblastoma (SH-SY5Y), adenocarcinomic alveolar basal epithelial (A549), cervical cancer (HeLa), HeLa contaminant (HEp2), pituitary epithelial-like (GH3), embryo (PA3I7) and osteosarcoma (U2OS) cells. *Indicates eight cell lines selected for further DXR cytotoxicity study.

Abbreviation: DXR, doxorubicin. 


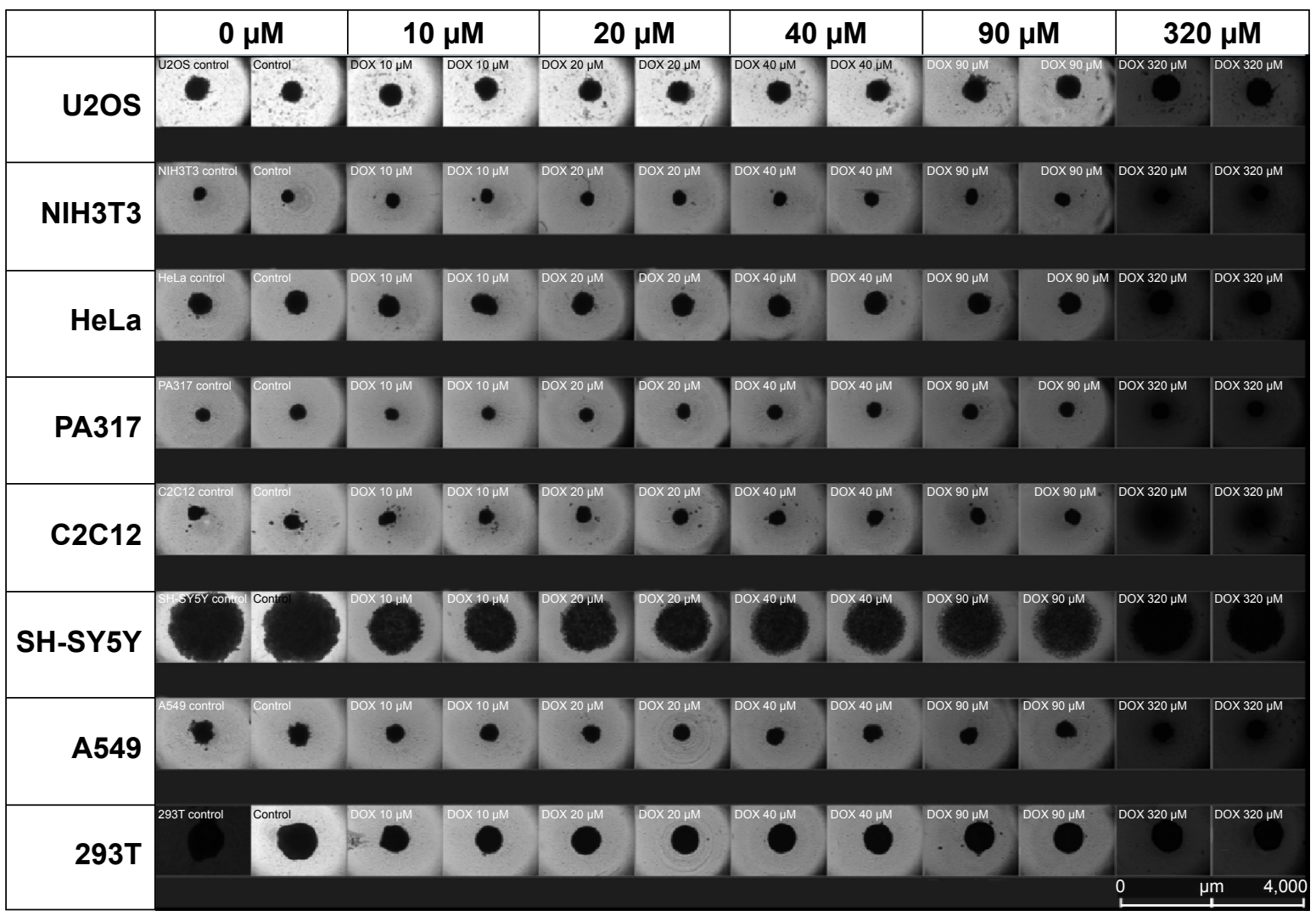

Figure 2 Compiled still shot photos of eight cell lines, NIH3T3, C2CI2, 293T, SH-SY5Y, A549, HeLa, PA3I 7 and U2OS in a 96 well plate, 5 days after doxorubicin treatment. One well of 293T cells was contaminated and revealed dark coloration. Other dark colorations at DXR $320 \mu$ Mere due to its high concentration.

Abbreviation: DXR, doxorubicin.

the shape and drug permeability. JuLI Stage continuous monitoring system was employed to observe the cellular changes over 5 days in the presence of various DXR concentrations, revealing physical changes. Since sizes and shapes of NIH3T3, PA317 and C2C12 cell lines were not affected by various concentrations of DXR, they were excluded in the follow-up study. The dark colorations of the wells at $320 \mu \mathrm{M}$ in all cell lines were due to high concentration of DXR with red color.

\section{The effects of DXR on the growth of 3D spheroids in real-time}

A549, HeLa, SH-SY5Y, U2OS and 293T spheroids were selected for detailed study. All spheroids treated with DXR were smaller in diameter after 5 days, which is documented in Table 1 and their changes shown in Figure 3. No significant difference in behavior was observed between spheroids treated with $20 \mu \mathrm{M}$ or higher concentrations of DXR. Over a time frame of $156 \mathrm{hrs}$ at $6 \mathrm{hrs}$ intervals the effects of 0 , $20,40 \mu \mathrm{M}$ and 0,10 and $20 \mu \mathrm{M}$ DXR concentrations on the viability of A549, HeLa, U2OS cell lines and SH-SY5Y and 293 T cell lines were recorded.

\section{HeLa cells}

The control HeLa spheroid without DXR was monitored and its diameter grew continuously over the entire period from $360 \mu \mathrm{M}$ at $0 \mathrm{hr}$ to $519 \mu \mathrm{M}$ at $156 \mathrm{hrs}$. Spheroids treated with 20 and $40 \mu \mathrm{M}$ DXR grew faster than the control until $24 \mathrm{hrs}$, and the diameter of spheroids shrank slowly until the end of the experiment. The changed diameter of DXR treated spheroids with 20 and $40 \mu \mathrm{M}$ concentrations were $43 \mu \mathrm{M}$ and $32 \mu \mathrm{M}$, respectively. When the spheroids were monitored in real-time, movements of cells were not visible after $24 \mathrm{hrs}$ from periphery of spheroid to the core. Spheroids retained their shape in all concentrations of DXR, indicating that the ECM

Table I Changes in the size $(\mu \mathrm{M})$ of spheroids

\begin{tabular}{|c|c|c|c|c|}
\hline \multirow[t]{2}{*}{ Cell line } & \multicolumn{4}{|c|}{ Doxorubicin $(\mu \mathrm{M})$} \\
\hline & Control 0 & 10 & 20 & 40 \\
\hline HeLa & $157 \pm 4$ & NA & $26 \pm 24$ & $25 \pm 9$ \\
\hline A549 & $-\mid 40 \pm 1$ & NA & $-190 \pm 23$ & $-188 \pm 14$ \\
\hline $293 \mathrm{~T}$ & $248 \pm 1$ & $-79 \pm 24$ & $-34 \pm 15$ & NA \\
\hline SH-SY5Y & $I, 25 I \pm I$ & $322 \pm 170$ & $329 \pm 8$ & NA \\
\hline U2OS & $-50 \pm I$ & NA & $-136 \pm 1$ & $-6 I \pm 23$ \\
\hline
\end{tabular}

Abbreviation: NA, not available. 


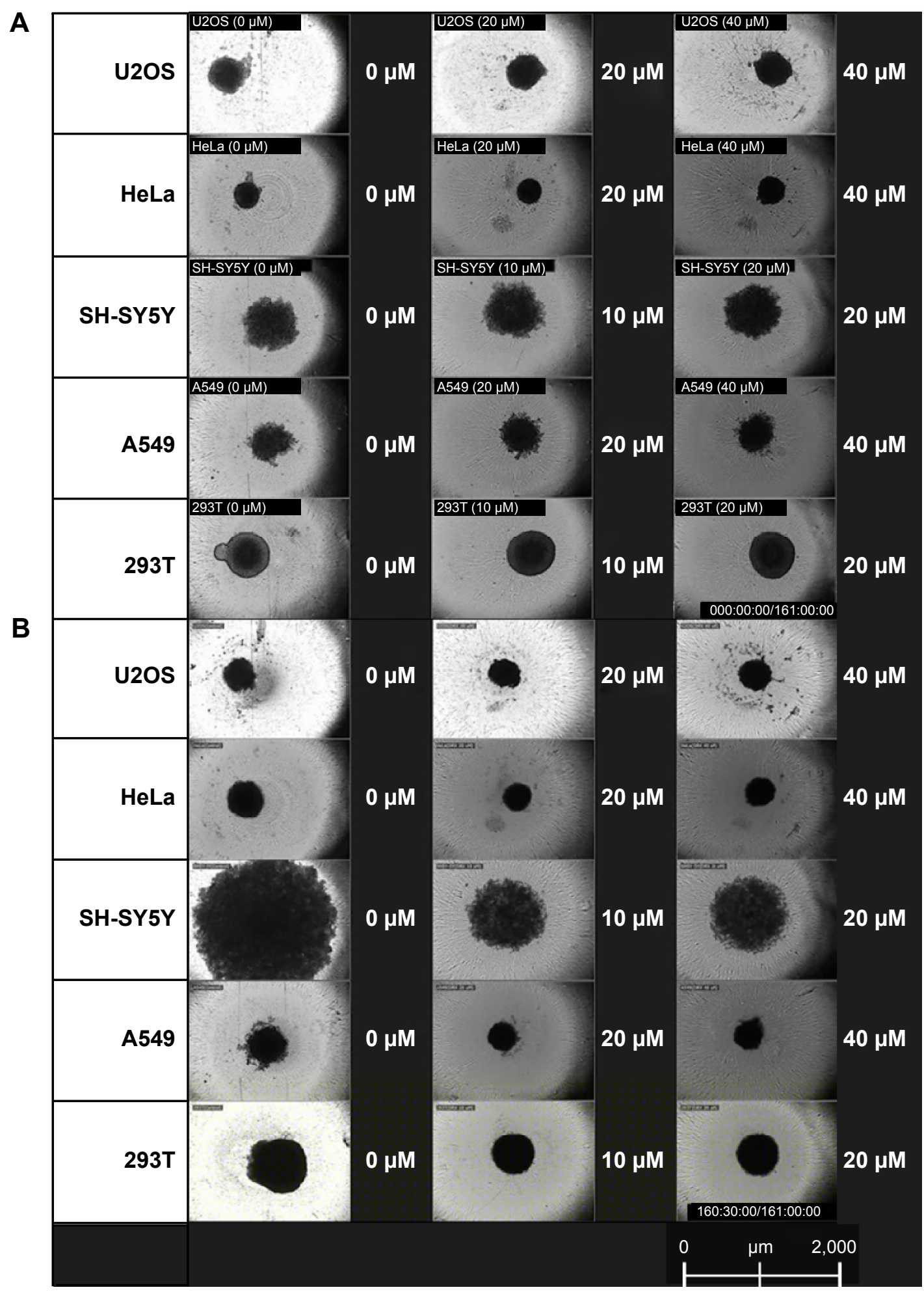

Figure 3 Still shots of five spheroid cell lines after DXR treatment. Spheroids treated with DXR at 0, 20, and $40 \mu M$ for U2OS, HeLa and A549, and with 0 , I0, and $20 \mu M$ for SH-SY5Y and 293T at time $0 \mathrm{~min}(\mathbf{A})$ and $158 \mathrm{~min}(\mathbf{B})$.

Abbreviation: DXR, doxorubicin.

was maintained, even after cell death. DXR treatments did not kill cells in the spheroids immediately, rather, it occurred after $24 \mathrm{hrs}$. These observations suggested that the internalization of DXR would have been needed to cause cytotoxicity.
A549 cells

After $156 \mathrm{hrs}$ of monitoring, the diameter of A549 spheroid controls decreased by a total of $141 \mu \mathrm{M}$. During that time, spheroids treated with 20 and $40 \mu \mathrm{M}$ of DXR also decreased, 
shrinking by $-206 \mu \mathrm{M}$ and $-178 \mu \mathrm{M}$, respectively, the rate of shrinkage was faster in the treated spheroids compared with the controls. Similar cellular movements were exhibited by all controls and DXR treated spheroids for the first $24 \mathrm{hrs}$. Arrests in cellular movements occurred from periphery to the core, indicating that A549 cells would not sustain the cytotoxicity of DXR at even $20 \mu \mathrm{M}$. Similar to HeLa spheroids, A549 spheroids retained their shape, supporting that ECM was still intact.

\section{T cells}

The $293 \mathrm{~T}$ control spheroids grew continuously for $156 \mathrm{hrs}$ increasing in size by $247 \mu \mathrm{M}$. Spheroids grew slowly for $6 \mathrm{hrs}$ after treatment with 10 and $20 \mu \mathrm{M}$ of DXR, then gradually contracted, finishing $89 \mu \mathrm{M}$ and $45 \mu \mathrm{M}$ smaller compared to the control. Cells at the periphery or the core of spheroids seemed to be active throughout the experiment, suggesting that DXR may stop cell division without complete cellular arrest. Also, 293T cells could have resistance towards DXR, or different metabolic processes for neutralizing DXR. The spheroid shape was intact in all treated cells.

\section{SH-SY5Y cells}

When the control SH-SY5Y spheroid without DXR was monitored for $156 \mathrm{hrs}$, the spheroid grew continuously from $798 \mu \mathrm{M}$ to $2,048 \mu \mathrm{M}$. Spheroids treated with 10 and $20 \mu \mathrm{M}$ DXR grew faster than the control until 24 hrs from the start of the treatments, where the diameters were $1,038 \mu \mathrm{m}$ and $1,249 \mu \mathrm{m}$ for treated cells with 10 and $20 \mu \mathrm{M}$ and $847 \mu \mathrm{M}$ for the control. An interesting phenomenon was observed only from DXR treated SH-SY5Y spheroids in comparison with other spheroids in this study. Even though diameter of DXR treated spheroids grew faster than the control, suggesting faster growth, DXR treated spheroids started to dismantle and cells became separated from each other, leading to cell death. This observation suggested that ECM was digested upon DXR treatment. The faster growth and delayed cell death until 24 hrs from the start of treatment could be due to the endocytosis of DXR, which needed to be internalized into the cytosol to become effective. In addition, various proteases could be released from the cells for the digestion of ECM and death. Upon closer examination of DXR treated spheroid with $10 \mu \mathrm{M}$, tiny cellular activities were observed at the core until the end of experiment.

\section{U2OS cells}

U2OS spheroids behaved similar to other A549, HeLa, U2OS and 293T spheroids. The difference in diameter for the control spheroids was $-49 \mu \mathrm{M}$, and cellular activities were continuously observed until the end of the experiment. Spheroids treated with 10 and $20 \mu \mathrm{M}$ DXR shrank by $-15 \mu \mathrm{M}$ and $-47 \mu \mathrm{M}$, respectively. Cellular activities were observed until $24 \mathrm{hrs}$ from the start of treatment and arrested afterwards; supporting that DXR could be effective after endocytosis, which would require $24 \mathrm{hrs}$.

A summary of the observable effects of DXR on the spheroid core, intermediate and periphery over time is shown in Table 2. For A549 and SH-SY5Y, there were no distinct periphery or intermediate regions. Proliferation in SH-SY5Y was observed at the core periphery and intermediate regions. Controls for U2OS and $293 \mathrm{~T}$ spheroids maintained a distinct periphery, intermediate and core over the course of the experiment, whereas the HeLa control exhibited an observable increase in cellular proliferation at the core and a loss in the intermediate region. The effects of increasing concentrations of DXR generally resulted in a densification of the spheroid core, loss in the intermediate regions and a drop in observable peripheral activity (motion). The advantage of spheroid densification to the cells initially led to a reduction in drug permeability and cellular ATP requirements. However, the

Table 2 The observable effects of DXR on multiple spheroidal cell lines over 24 hours

\begin{tabular}{|c|c|c|c|c|}
\hline Cell line & $\begin{array}{l}\text { Spheroid } \\
\text { periphery }\end{array}$ & $\begin{array}{l}\text { Spheroid } \\
\text { intermediate }\end{array}$ & $\begin{array}{l}\text { Spheroid } \\
\text { core }\end{array}$ & $\begin{array}{l}\text { Spheroid } \\
\text { expansion/motion }\end{array}$ \\
\hline 293T control & Yes & Yes & Yes & Yes/Yes \\
\hline 293T DXR $20 \mu \mathrm{M}$ & No & No & No & No/Yes \\
\hline A549 control & Yes & No & Yes & Yes/Yes \\
\hline A549 DXR $40 \mu \mathrm{M}$ & No & No & No & $\mathrm{No} / \mathrm{No}$ \\
\hline HeLa control & Yes & No & Yes & Yes/Yes \\
\hline HeLa DXR $40 \mu \mathrm{M}$ & No & No & No & $\mathrm{No} / \mathrm{No}$ \\
\hline SH-SY5Y control & Yes & Yes & Yes & Yes/Yes \\
\hline SH-SY5Y DXR $20 \mu \mathrm{M}$ & No & No & No & $\mathrm{No} / \mathrm{No}$ \\
\hline U2OS control & Yes & Yes & Yes & Yes/Yes \\
\hline U2OS DXR $40 \mu \mathrm{M}$ & No & No & No & $\mathrm{No} / \mathrm{No}$ \\
\hline
\end{tabular}

Abbreviation: DXR, doxorubicin. 

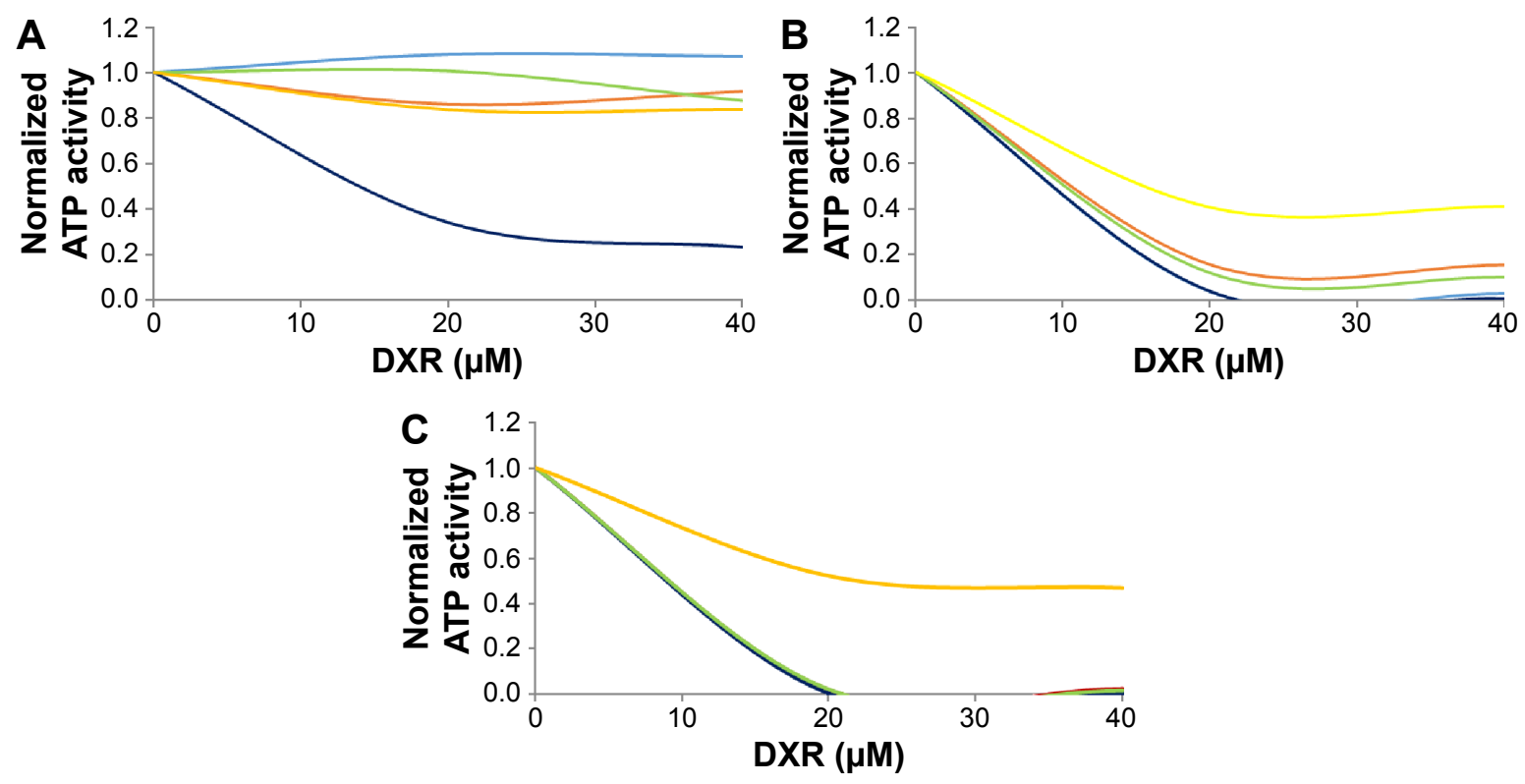

- U2OS - HeLa - SH-SY5Y - A549-293T

Figure 4 The effect of increasing doxorubicin (DXR) concentrations on U2OS, HeLa, SH-SY5Y, A549 and 293T spheroidal ATP activity after (A) I day (B) 3 days' and (C) 5 days' incubation.

high concentrations of DXR used herein induced quite a unique reaction from the SH-SY5Y spheroids causing them to rapidly expand then collapse in less than $24 \mathrm{hrs}$. From the examination of the real-time data, SH-SY5Y spheroids could be classified as "compact aggregate" similar to breast carcinoma MDA-MB-231 spheroids, which had higher ATP requirements than tight spheroids. The aggregate nature of this type of spheroid coupled with the lack of an established periphery would allow DXR to permeate very quickly throughout the spheroid. However, the aggregates at the core (higher magnification) did remain active for several hrs after the collapse, which suggests the ECM within the aggregates themselves limited the permeation of DXR, prolonging the activity of the cells, and the ECM is heterogeneous in nature.

\section{D cell viability assay: measuring ATP production in comparison with anti- proliferation assay}

DXR produces ROS, causing damage to mitochondria leading to decreased glutathione levels, mitochondrial membrane depolarization, calcium release into the matrix and mitochondrial permeability transition pore opening and impairment of ATP synthesis and decreased ATP levels. DXR induced nephropathy would occur, when the drug interfered with the mitochondrial activity, reducing the activity of complexes I and IV. Figure 4 and Table 3 showed the change in the metabolic activity of HeLa, A549, 293T, SH-SY5Y, and U2OS spheroids incubated in increasing DXR concentrations for 1, 3 and 5 days. The same degree of sensitivity from the 2D system did not translate to a 3D culture system, resulting in higher IC50 values than the $2 \mathrm{D}$ system. These varying sensitivities seen in both $2 \mathrm{D}$ and $3 \mathrm{D}$ systems to DXR are most probably due to the under- or over-expression of the BID which can sensitize certain cancer cell lines to apoptosis. Recently it was reported that over-expression of BID can strongly sensitize HeLa, A549 and other cell lines to DXR, and that the extent of sensitization of particular cell lines by BID is specific for DXR and does not overlap with those observed for TNF-related apoptosis-inducing ligand or camptothecin. ${ }^{41}$ The difference in DXR sensitivities regarding the 2 and 3D models is due to cells in the 2D model being well oxygenated resulting in the rapid build-up of ROS when

Table 3 Comparison of doxorubicin IC50 values of A549, 293T, HeLa, U2OS, and SH-SY5Y spheroids and effects over the incubation times

\begin{tabular}{|c|c|c|c|c|}
\hline \multirow{2}{*}{$\frac{\text { Doxorubicin }}{\text { Cell cultures }}$} & \multicolumn{4}{|c|}{ IC50 value $(\mu \mathrm{M})$} \\
\hline & 2D & 3D (day I) & 3D (day 3) & 3D (day 5) \\
\hline A549 & $1.5^{41}$ & NR & 11 & 10.1 \\
\hline $293 T$ & $2.6^{42}$ & NR & 16.5 & 26 \\
\hline HeLa & $1.0^{41}$ & NR & 11.2 & 9.6 \\
\hline U2OS & $0.3^{43}$ & NR & 9.7 & 10.7 \\
\hline SH-SY5Y & $0.08^{44}$ & 15 & 9.5 & 10 \\
\hline $\mathrm{SaOS}-2$ & $0.12^{41}$ & $0.3^{41}$ & NR & NR \\
\hline HOS & $0.12^{41}$ & $2.5^{41}$ & NR & NR \\
\hline
\end{tabular}

Abbreviation: NR, IC50 not reached. 
exposed to DXR. However the opposite is true for cells at the spheroid core which makes them far more resistant.

After 24 hrs, 4 out of 5 of the spheroids did not show any significant change in their metabolic activity, when incubated with increasing concentrations of DXR. This observation at the initial stage could be attributed to spheroid densification and a reduction in drug permeability. However, the metabolic activity of HeLa, A549, SH-SY5Y, and U2OS spheroids at Day 3 had essentially collapsed with the exception of 293 T. This trend was repeated on Day 5, except the metabolic activity of 293 T was improved. In vivo, the high level of DXR induced peroxides would be expected to kill 293T (kidney cells) causing them to leak proteins leading to glomerulosclerosis and eventually kidney failure. Unlike the liver, the ability of the kidney to regenerate itself is generally poor, reducing its ability to heal itself even when glomeruli are damaged. Yet, HeLa spheroids were effectively dead by Day 3, whereas 293T spheroids (kidney cell line) remained active. In our humble opinion, the increased metabolic resistance seen in 293T from Day 3 to Day 5 could be attributed to enhanced ceramide production and over-expression of glucosylceramide genes (GCS). It might also be theorized that DXR increased ceramide production by activating sphingomyelinase. ${ }^{34}$ Taken together, these two processes were suspected to induce a positive feedback cycle through Sp1, generating an anti-apoptotic force. However, the most likely explanation for the high metabolic activity seen with $293 \mathrm{~T}$ could be that the cells were ABCB8 mediated, and the genome of the mitochondria is protected through an ATP binding cassette.

In conclusion, cytotoxicity of DXR against 3D-spheroids of adenocarcinomic alveolar basal epithelial (A549), cervical cancer (HeLa), neuroblastoma (SH-SY5Y), osteosarcoma (U2OS), and embryonic kidney (HEK293T) cell lines were investigated in real-time with JuLi Stage in comparison with measuring ATP production. Continuous monitoring of 5 sets of 3D-spheroid forms in the presence of DXR pointed out that it needed to be internalized by endocytosis to be effective, since all cytotoxicities of all spheroids were visible after 1 day of the treatment. Performing 3D cell cultures, anti-proliferation assay, apoptosis assays and other continuous monitoring of experiments over many days would be beneficial in studying wound healing, apoptosis, drug treatments, transfection efficiency, stem cell differentiations and tissue engineering.

\section{Acknowledgment}

This work was supported from GRRC program of Gyeonggi province (GRRC Gachon 2016-B02, Development of Nanomaterials for Biomedical Sensing Applications).

\section{Disclosure}

The authors report no conflicts of interest in this work.

\section{References}

1. Folberg R, Arbieva Z, Moses J, et al. Tumor cell plasticity in uveal melanoma: microenvironment directed dampening of the invasive and metastatic genotype and phenotype accompanies the generation of vasculogenic mimicry patterns. Am J Pathol. 2006;169(4):1376-1389.

2. Maienschein J. Regenerative medicine's historical roots in regeneration, transplantation, and translation. Dev Biol. 2011;358(2):278-284.

3. Letinsky MS, Morrison-Graham K. Structure of developing frog neuromuscular junctions. J Neurocytol. 1980;9(3):321-342.

4. Masters JR. HeLa cells 50 years on: the good, the bad and the ugly. Nat Rev Cancer. 2002;2(4):315-319.

5. Lucey BP, Nelson-Rees WA, Hutchins GM. Henrietta Lacks, HeLa cells, and cell culture contamination. Arch Pathol Lab Med. 2009;133(9): 1463-1467.

6. Netti PA, Berk DA, Swartz MA, Grodzinsky AJ, Jain RK. Role of extracellular matrix assembly in interstitial transport in solid tumors. Cancer Res. 2000;60(9):2497-2503.

7. Pluen A, Boucher Y, Ramanujan S, et al. Role of tumor-host interactions in interstitial diffusion of macromolecules:cranial vs. subcutaneous tumors. Proc Natl Acad Sci U S A. 2001;98(8):4628-4633.

8. Wang X, Zhien X, Wang J, et al. Doxorubicin delivery to 3D multicellular spheroids and tumors based on boronic acid-rich chitosan nanoparticles. Biomaterials. 2013;34(19):4667-4679.

9. Goodman TT, Ng CP, Pun SH. 3-D tissue culture systems for the evaluation and optimization of nanoparticle-based drug carriers. Bioconjug Chem. 2008;19(10):1951-1959.

10. Vinci M, Gowan S, Boxall F, et al. Advances in establishment and analysis of three-dimensional tumor spheroid-based functional assays for target validation and drug evaluation. BMC Biol. 2012;10:29.

11. Lee JM, Mhawech-Fauceglia P, Lee N, et al. A three-dimensional microenvironment alters protein expression and chemosensitivity of epithelial ovarian cancer cells in vitro. Lab Invest. 2013;93(5): $528-542$.

12. Weiswald LB, Bellet D, Dangles-Marie V. Spherical cancer models in tumor biology. Neoplasia. 2015;17(1):1-15.

13. Eglen RM, Randle DH. Drug Discovery Goes Three-Dimensional: Goodbye to Flat High-Throughput Xcreening? Assay Drug Dev Technol. 2015;13(5):262-265.

14. Wartenberg M, Donmez F, Ling FC, et al. Tumor induced angiogenesis studied in confrontation cultures of multicellular tumor spheroids and embryoid bodies grown from pluripotent embryonic stem cells. FASEBJ. 2001;15(6):995-1005.

15. Unsworth BR, Lelkes PI. Growing tissues in microgravity. Nat Med. 1998; 4(8):901-907

16. Del Duca D, Werbowetski T, Del Maestro RF. Spheroid preparation from hanging drops: characterization of a model of brain tumor invasion. J Neurooncol. 2004;67(3):295-303.

17. Takaishi S, Okumura $\mathrm{T}, \mathrm{Tu} \mathrm{S}$, et al. Identification of gastric cancer stem cells using the cell surface marker CD44. Stem Cells. 2009;27(5): $1006-1020$.

18. Hardelauf H, Frimat JP, Stewart JD, et al. Microarrays for the scalable production of metabolically relevant tumour spheroids: a tool for modulating chemosensitivity traits. Lab Chip. 2011;11(3):419-428.

19. Fitzgerald KA, Malhotra M, Curtin CM, O’Brien FJ, O’Driscoll CM. Life in 3D is never flat: 3D models to optimise drug delivery. J Control Release. 2015;215:39-54.

20. Mikhail AS, Eetezadi S, Allen C. Multicellular tumor spheroids for evaluation of cytotoxicity and tumor growth inhibitory effects of nanomedicines in vitro: a comparison of docetaxel-loaded block copolymer micelles and Taxotere ${ }^{\circledR}$. PLoS One. 2013;8(4):e62630.

21. Pang B, Qiao X, Janssen L, et al. Drug-induced histone eviction from open chromatin contributes to the chemotherapeutic effects of doxorubicin. Nat Commun. 2013;4:1908. 
22. Wang CW, Chen CL, Wang CK, et al. Cisplatin-, Doxorubicin-, and Docetaxel-Induced Cell Death Promoted by the Aqueous Extract of Solanum nigrum in Human Ovarian Carcinoma Cells. Integr Cancer Ther. 2015;14(6):546-555.

23. Sanchis J, Canal F, Lucas R, Vicent MJ. Polymer-drug conjugates for novel molecular targets. Nanomedicine (Lond). 2010;5(6):915-935.

24. Ben-Aharon I, Shalgi R. What lies behind chemotherapy-induced ovarian toxicity? Reproduction. 2012;144(2):153-163.

25. Wu CC, Li TK, Farh L, et al. Structural basis of type II topoisomerase inhibition by the anticancer drug etoposide. Science. 2011;333(6041): $459-462$.

26. Sorensen BS, Sinding J, Andersen AH, et al. Mode of action of topoisomerase II-targeting agents at a specific DNA sequence, uncoupling the DNA binding, cleavage and religation events. J Mol Biol. 1992; 228(3):778-786

27. Zhang S, Liu X, Bawa-Khalfe T, et al. Identification of the molecular basis of Doxorubicin-induced cardiotoxicity. Nat Med. 2012;18(11): 1639-1642.

28. Vavrova A, Jansova H, Mackova E, et al. Catalytic inhibitors of topoisomerase II differently modulate the toxicity of anthracyclines in cardiac and cancer cells. PLoS One. 2013;8(10):e76676.

29. Lin LT, Tai CJ, Su CH, et al. The Ethanolic Extract of Taiwanofungus camphoratus (Antrodia camphorata) Induces Cell Cycle Arrest and Enhances Cytotoxicity of Cisplatin and Doxorubicin on Human Hepatocellular Carcinoma Cells. BioMed Research International. 2015;2015:415269.

30. Flores-Pérez A, Rafaelli LE, Ramírez-Torres N, et al. RAD50 targeting impairs DNA damage response and sensitizes human breast cancer cells to cisplatin therapy. Cancer Biol Ther. 2014;15(6):777-788.

31. Senchenkov A, Litvak DA, Cabot MC. Targeting ceramide metabolism a strategy for overcoming drug resistance. J Natl Cancer Inst. 2001; 93(5):347-357.

32. Strigun A, Wahrheit J, Niklas J, Heinzle E, Noor F. Doxorubicin increases oxidative metabolism in HL-1 cardiomyocytes as shown by 13C metabolic flux analysis. Toxicol Sci. 2012;125(2):595-606.

33. Bates DA, Winterbourn CC. Deoxyribose breakdown by the Adriamycin semiquinone and $\mathrm{H}_{2} \mathrm{O}_{2}$ : evidence for hydroxyl radical participation. FEBS Lett. 1982;145(1):137-142.
34. Zhang $P$, Wang $C$, Zhao J, et al. Near Infrared-Guided Smart Nanocarriers for Micro-RNA Controlled Release of Doxorubicin/siRNA with intracellular ATP as Fuel. ACS Nano. 2016;10(3):3637-3647.

35. Köppen C, Reifschneider O, Castanheira I, et al. Quantitative imaging of platinum based on laser ablation-inductively coupled plasma-mass spectrometry to investigate toxic side effects of cisplatin. Metallomics. 2015;7(12):1595-1603.

36. Flores-Pérez A, Rafaelli LE, Ramírez-Torres N, et al. RAD50 targeting impairs DNA damage response and sensitizes human breast cancer cells to cisplatin therapy. Cancer Biol Ther. 2014;15(6):777-788.

37. Gambari R, Hau DK, Wong WY, Chui CH. Sensitization of Hep3B hepatoma cells to cisplatin and doxorubicin by corilagin. Phytother Res. 2014;28(5):781-783.

38. Ravi M, Paramesh V, Kaviya SR, Anuradha E, Solomon FD. 3D cell culture systems: advantage and applications. J Cell Physiol. 2015; 230(1):16-26

39. Rimann M, Laternser S, Gvozdenovic A, et al. An in vitro osteosarcoma 3D microtissue model for drug development. J Biotechnol. 2014; 189:129-135.

40. Jaganathan H, Gage J, Leonard F, et al. Three-dimensional in vitro co-culture model of breast tumor using magnetic levitation. Sci Rep. 2014;4:6468.

41. Orzechowska EJ, Girstun A, Staron K, Trzcinska-Danielewicz J. Synergy of BID with doxorubicin in the killing of cancer cells. 2015; 33(5):2143-2150.

42. Grosicki M, Latacz G, Szopa A, Cukier A, Kieć-Kononowicz K. The study of cellular cytotoxicity of argireline - an anti-aging peptide. Acta Biochim Pol. 2014;61(1):29-32.

43. Graat HC, Witlox MA, Schagen FH. Different susceptibility of osteosarcoma cell lines and primary cells to treatment with oncolytic adenovirus and doxorubicin or cisplatin. Br J Cancer. 2006;94(12): 1837-1844.

44. Palmberg E, Johnsen JI, Paulsson J. Metronomic scheduling of imatinib abrogates clonogenicity of neuroblastoma cells and enhances their susceptibility to selected chemotherapeutic drugs in vitro and in vivo. Int J Cancer. 2009;124(5):1227-1234. 


\section{Supplementary materials}

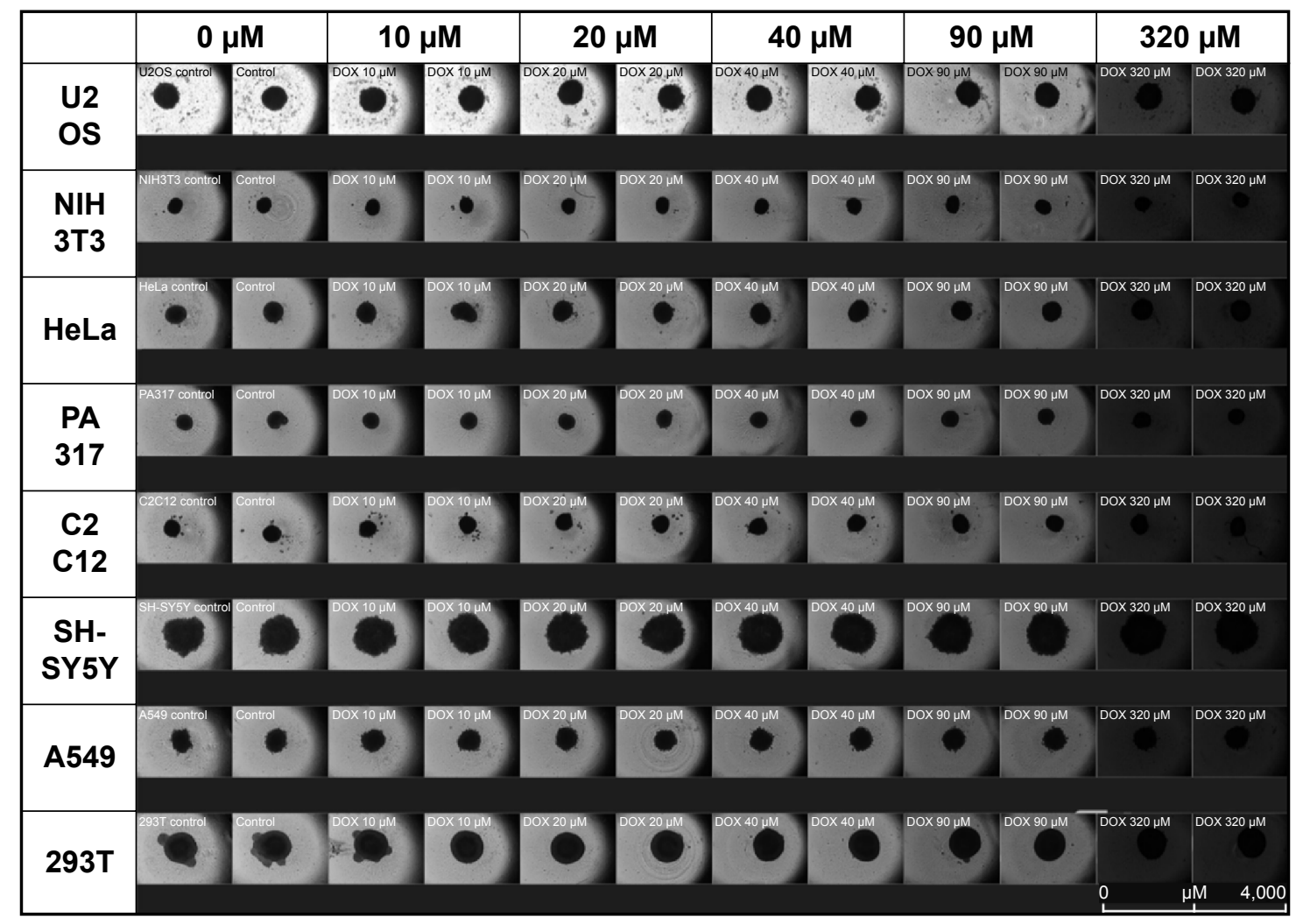

Figure $\mathbf{S I}$ Still shots of 8 spheroid cell lines at I day after DXR treatment. Abbreviation: DXR, doxorubicin. 


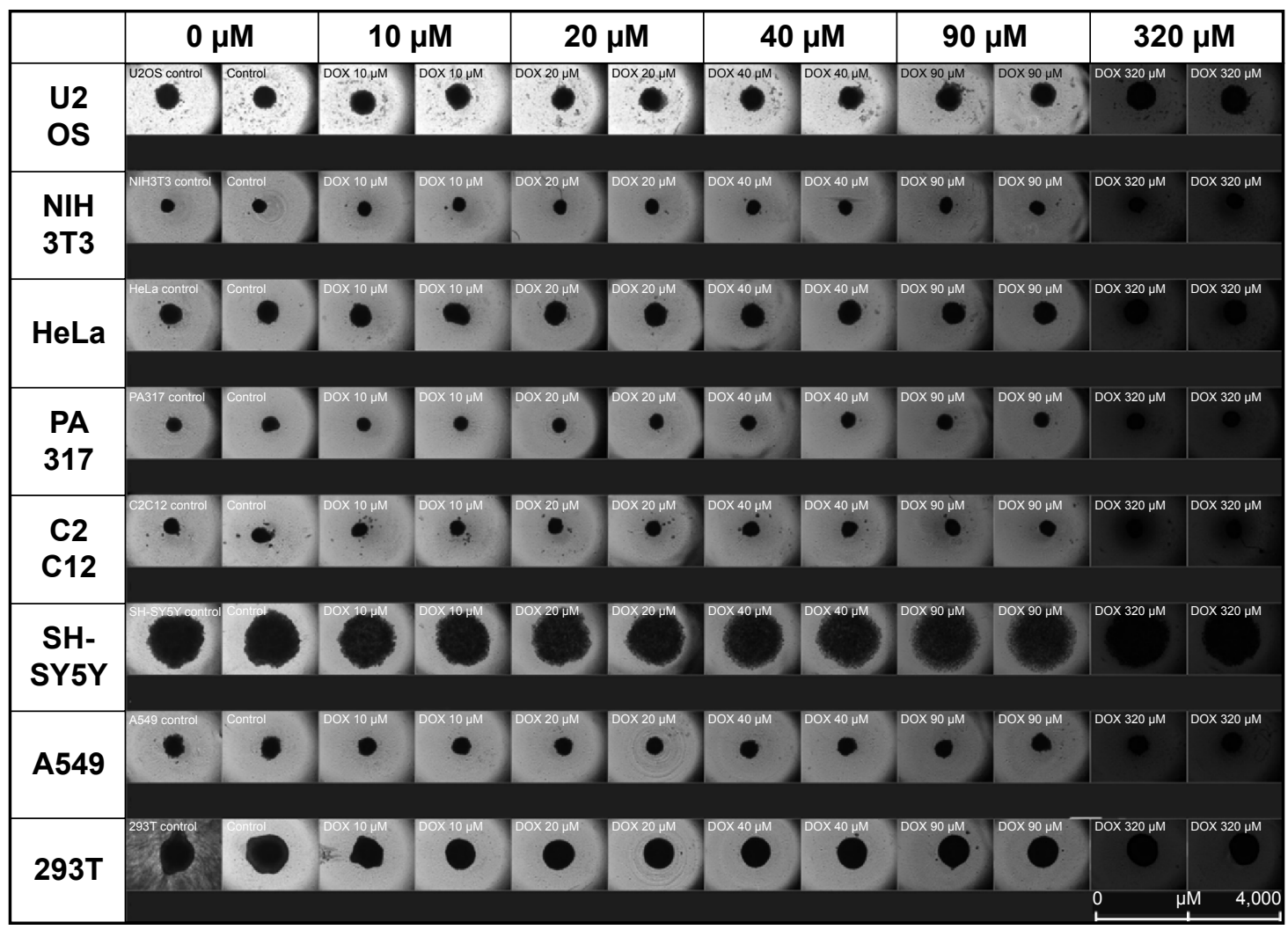

Figure S2 Still shots of 8 spheroid cell lines at 3 days after DXR treatment. Abbreviation: DXR, doxorubicin.

OncoTargets and Therapy

\section{Publish your work in this journal}

OncoTargets and Therapy is an international, peer-reviewed, open access journal focusing on the pathological basis of all cancers, potential targets for therapy and treatment protocols employed to improve the management of cancer patients. The journal also focuses on the impact of management programs and new therapeutic agents and protocols on

\section{Dovepress}

patient perspectives such as quality of life, adherence and satisfaction The manuscript management system is completely online and includes a very quick and fair peer-review system, which is all easy to use. Visit http://www.dovepress.com/testimonials.php to read real quotes from published authors. 